\title{
Journal of Phase Equilibria and Diffusion Announces Editorial Transition
}

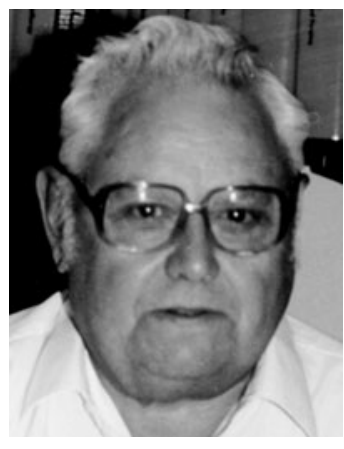

Jack Smith

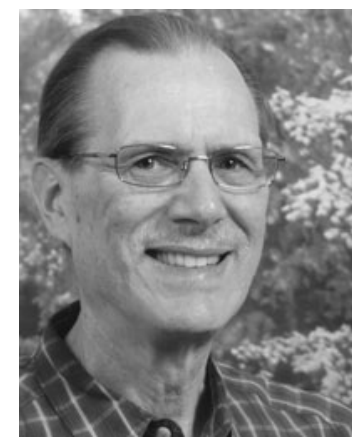

John Morral

After 24 years of serving as editor of the ASM Journal of Phase Equilibria and Diffusion (JPED), Prof. John "Jack" F. Smith, FASM, has transferred his responsibilities to Prof. John E. Morral, FASM. Jack became editor while the publication was titled the Bulletin of Alloy Phase Diagrams and contained mainly phase diagram evaluations. He led the journal through its transition in 1991 to the Journal of Phase Equilibria and the addition of basic and applied research papers in each issue, as well as the subsequent broadening of the journal's scope in 2004 to include a larger emphasis on diffusion, when it took on its current title. Jack's vision, persistent efforts, and continual attention to high quality have made JPED a unique publication among the many journals in existence today.

In addition to his long tenure as journal editor, Jack served as the ASM/ National Bureau of Standards (now NIST) Data Program for Alloy Phase Diagrams Category Editor for binary vanadium alloys and Co-category editor for binary niobium alloys. During his career, he served as Chair of the Department of Metallurgy at Iowa State University and as Division Chief, Metallurgy Division, Ames Laboratory. He was elected Fellow of the American Institute of Chemists in 1969 and of ASM in 1984. In 2007, Jack was named an International Member of the Polish Academy of Arts and Sciences in honor of his contribution to Polish-American scientific cooperation. He authored more than 180 technical papers, as well as a book on thorium. His publications have been concerned with crystallography, thermodynamics, elasticity, and other physical properties of alloy phases. The ultrasonic techniques associated with his elasticity work led to extensive work and publication in nondestructive evaluation. An avid pilot, Jack is featured in the Hall of Memories of the Antique Airplane Association, headquartered with a museum in Blakesburg, Iowa. The display on Jack there includes the dust jacket of his book, Hellcats over the Philippine Deep, and photos from his service during World War II and of some interesting airplanes he has flown. The organization was founded in 1953 with the intent of restoring old airplanes and of keeping them in airworthy condition, and Jack has been a member since 1956.

We thank Jack for unceasingly supplying his insight and dedication as he has skillfully led the journal for the past 24 years and also for providing for the future success of JPED by identifying a capable and qualified successor. Although we will certainly miss our interactions with Jack, we are delighted that John has accepted the appointment as editor and thank him for accepting this new responsibility.

John recently retired from the Ohio State University where he was a Professor of Materials Science and Engineering and former Department Chair. Previously he spent 30 years at the University of Connecticut where he was Department Head and retired as an Emeritus Professor in 2003. He graduated in 1969 with a Ph.D. from M.I.T. where he was advised by John W. Cahn. He is a long time member of the ASM Alloy Phase Diagram Committee and has been Deputy Editor of JPED since 1997. Over the years he has organized over a dozen National and International symposia including two international conferences for ASM on Heat Treating. He has edited seven conference proceedings and published over a hundred research journal articles. His awards include being named a fellow of ASM International, an American Competitiveness and Innovation fellow of the NSF Division of Materials Research, a Distinguished Scientist/ Engineer by the EPMP Division of TMS, and a Distinguished Alumnus by the Ohio State University College of Engineering.

John's research interests include multicomponent diffusion and phase diagrams, high temperature coatings, gas/solid reactions, phase transformations, heat treatment, and irradiation damage. His career has focused on extending thermodynamic and kinetic concepts that are well known for binaries to ternary and higher order systems. The objective has been to show which concepts are the same and which are new and different when dealing with complex alloys, especially regarding interdiffusion and phase diagrams.

We welcome our new editor, and are confident that he will provide a similarly skillful stewardship for the journal as Jack has done in the past. We wish Jack all the best in his retirement and we wish John satisfaction and success as the new editor.

\author{
Dr. Patrice Turchi \\ Chair \\ Alloy Phase Diagram Committee \\ Mary Anne Fleming \\ Senior Content Developer, Journals \\ ASM International
}

